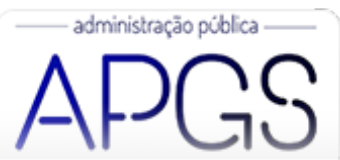

Administração Pública e Gestão Social ISSN: 2175-5787

apgs@ufv.br

Universidade Federal de Viçosa

Brasil

\title{
Práticas de Contabilidade Gerencial no Terceiro Setor: O Desafio da Gestão Eficiente
}

Innocenti, Renícia; Gasparetto, Valdirene

Práticas de Contabilidade Gerencial no Terceiro Setor: O Desafio da Gestão Eficiente

Administração Pública e Gestão Social, vol. 13, núm. 3, 2021

Universidade Federal de Viçosa, Brasil

Disponible en: https://www.redalyc.org/articulo.oa?id=351566982008 


\title{
Práticas de Contabilidade Gerencial no Terceiro Setor: O Desafio da Gestão Eficiente
}

\section{Management Accounting Practices in Non-Profit Organizations: The Challenge of Efficient Management Prácticas de Contabilidad Gerencial en el Tercer Sector: El Desafío de la Gestión Eficiente}

\author{
Renicia Innocenti \\ Universidade Federal de Santa Catarina, Brasil \\ reniciamaria2008@hotmail.com \\ Valdirene Gasparetto \\ Universidade Federal de Santa Catarina, Brasil \\ valdirene.gasparetto@ufsc.br
}

Redalyc: https://www.redalyc.org/articulo.oa?

\section{Resumo:}

Objetivo: Verificar se a implementação de práticas de contabilidade gerencial em uma organização do terceiro setor brasileiro apoia o alcance da eficiência organizacional, sob as especificidades de organizações sem fins lucrativos.

Enquadramento teórico: Por meio da abordagem institucional, em que pressões internas e externas influenciam a adoção e a mudança de práticas, o estudo apresenta a contabilidade gerencial como suporte à gestão eficiente das demandas técnicas e sociais de organizações do terceiro setor brasileiro. Nesse segmento social, as organizações atuam por melhores resultados e para atender expectativas da sociedade, na busca de eficiência e apoio social.

Metodologia: Pesquisa de natureza descritiva com abordagem qualitativa, realizada por meio de levantamento, aplicada em uma fundação privada educacional brasileira. A coleta de dados foi efetuada por meio de documentos e questionário. $\mathrm{Na}$ análise dos dados foi utilizada análise qualitativa de conteúdo e estatística descritiva.

Resultados: A implementação das práticas de contabilidade gerencial foi orientada por eficiência, para o atendimento das demandas técnicas da Fundação, em prol de sua sustentabilidade, e das demandas sociais, para concretizar sua missão. Práticas tradicionais de contabilidade gerencial são efetivamente conhecidas e utilizadas e têm um papel decisivo no processo de gestão da Fundação, contribuindo para o alcance da eficiência organizacional.

Originalidade: A pesquisa preenche uma demanda por pesquisas empíricas que apresentem a contabilidade gerencial como um meio de sustentar a gestão eficiente das demandas técnicas e sociais de organizações do terceiro setor brasileiro, em prol da sua continuidade nesse ambiente social.

Contribuições teóricas e práticas: $\mathrm{O}$ estudo contribui por ampliar o conhecimento sobre a contabilidade gerencial no terceiro setor, área negligenciada na literatura contábil, sugerindo novos estudos. Como contribuição prática, demonstra-se que a implementação de práticas de contabilidade gerencial em organizações do terceiro setor permite alcançar eficiência organizacional, com a adaptação dos conceitos de gestão tradicionais à realidade desse segmento social, sem desrespeitar seus princípios norteadores. Palavras-Chave: Contabilidade Gerencial, Eficiência, Fundação Privada, Terceiro Setor.

\section{ABstraCt:}

Purpose: The purpose of this essay is to verify if the implementation of management accounting practices in a Brazilian third sector organization supports the achievement of organizational efficiency, under the specificities of non-profit organizations.

Theoretical framework: Through the institutional approach, in which internal and external pressures influence the adoption and change of practices, the study presents management accounting as a support for the efficient management of the technical and social demands of organizations in the Brazilian third sector. In this social segment, organizations work for better results and to meet society's expectations, in the search for efficiency and social support.

Methodology: Research of a descriptive nature with a qualitative approach, carried out through a survey, applied in a private Brazilian educational foundation. Data collection was carried out using documents and survey. In data analysis, qualitative content analysis and descriptive statistics were used. 
Results: The implementation of management accounting practices was guided by efficiency, to meet the technical demands of the Foundation, in favor of its sustainability and social demands, to achieve its mission. Traditional management accounting practices are effectively known and used and have a decisive role in the Foundation's management process, contributing to the achievement of organizational efficiency.

Originality: The research fills a demand for empirical research that presents management accounting as a means of sustaining the efficient management of the technical and social demands of organizations in the Brazilian third sector, in favor of their continuity in this social environment.

Theoretical and practical contributions: The study contributes to expand the knowledge about management accounting in the third sector, a neglected area in the accounting literature, suggesting new studies. As a practical contribution, it is demonstrated that the implementation of management accounting practices in third sector organizations allows to achieve organizational efficiency, with the adaptation of traditional management concepts to the reality of this social segment, without disrespecting its guiding principles.

KEYWORDs: Management Accounting, Efficiency, Private Foundation, Non-Profit Organizations.

\section{RESUMEN:}

Objetivo: Verificar si la implementación de prácticas de contabilidad gerencial en una organización brasileña del tercer sector apoya el logro de la eficiencia organizacional, bajo las especificidades de las organizaciones sin fines de lucro.

Marco teórico: A través del enfoque institucional, en el que presiones internas y externas influyen en la adopción y cambio de prácticas, el estudio presenta la contabilidad gerencial como un soporte para la gestión eficiente de las demandas técnicas y sociales de las organizaciones del tercer sector brasileño. En este segmento social, las organizaciones trabajan para obtener mejores resultados y cumplir con las expectativas de la sociedad, en la búsqueda de la eficiencia y el apoyo social.

Metodología: Investigación de carácter descriptivo con enfoque cualitativo, realizada a través de una encuesta, aplicada en una fundación educativa privada brasileña. La recolección de datos se llevó a cabo mediante un cuestionario y documentos. En el análisis de datos se utilizó análisis de contenido cualitativo y estadística descriptiva.

Resultados: La implementación de las prácticas de contabilidad gerencial estuvo guiada por la eficiencia, para satisfacer las demandas técnicas de la Fundación, en favor de su sustentabilidad, y las demandas sociales, para lograr su misión. Las prácticas tradicionales de contabilidad gerencial son conocidas y utilizadas de manera eficaz y tienen un papel decisivo en el proceso de gestión de la Fundación, contribuyendo al logro de la eficiencia organizativa.

Originalidad: La investigación responde una demanda de investigación empírica que presenta la contabilidad gerencial como un medio para sustentar la gestión eficiente de las demandas técnicas y sociales de las organizaciones del tercer sector brasileño, a favor de su continuidad en este entorno social.

Aportes teóricos y prácticos: El estudio contribuye a ampliar el conocimiento sobre la contabilidad gerencial en el tercer sector, un área desatendida en la literatura contable, sugiriendo nuevos estudios. Como aporte práctico, se demuestra que la implementación de prácticas de contabilidad gerencial en organizaciones del tercer sector permite lograr la eficiencia organizacional, con la adecuación de los conceptos tradicionales de gestión a la realidad de este segmento social, sin faltar al respeto a sus principios rectores.

Palabras clave: Contabilidad Gerencial, Eficiencia, Fundación Privada, Tercer Sector.

\section{INTRODUÇÃo}

Diversas ações da sociedade civil são apoiadas pelo terceiro setor, cujas características envolvem a participação voluntária, autônoma e privada, organizada em torno de objetivos coletivos ou de interesse público (Salamon \& Anheir, 1997). O terceiro setor posiciona-se entre o estado e o mercado e conjuga as finalidades do primeiro e a natureza do segundo, ou seja, contempla organizações que visam benefícios coletivos (sem integrar o governo) e de natureza privada (sem auferir lucros) (Silva, 2010). Embora essas organizações não visem lucro, é vital o alcance de resultado positivo para a sua continuidade (Silveira \& Borba, 2010).

No Brasil, a formação do terceiro setor contempla a relação da sociedade civil com o estado, que não centraliza em si todas as responsabilidades pelo desenvolvimento social (Salamon \& Anheir, 1997). Nesse contexto, as entidades do terceiro setor brasileiro atuam como coparceiras dos entes públicos em ações voltadas à coletividade (Fischer \& Falconer, 1998). Por prestar serviços de interesse público, as entidades do terceiro setor podem pleitear, junto ao poder público, títulos e certificações que resultam em benefícios 
fiscais para seus doadores, isenções tributárias e parcerias com o governo, nas distintas esferas governamentais (Guerra \& Aguiar, 2007).

As entidades do terceiro setor apresentam características conceituais e legais necessárias ao desenvolvimento de suas atividades, visando a maximizar recursos para atender às demandas sociais. Essas especificidades advêm de leis, títulos e registros, obrigações perante órgãos públicos e requisitos para manter imunidade e isenção tributária (Voese \& Reptczuk, 2011). A existência de uma organização do terceiro setor, ou a validade da sua causa, era suficiente para justificar o aporte de recursos. Contudo, os financiadores passaram a exigir apresentação periódica de resultados, como desempenho, número de beneficiários assistidos, aplicação de recursos etc. (Guerra \& Aguiar, 2007). Conforme Persson e Moretto (2020), "há uma tendência da lógica estratégica do mercado em invadir os domínios das organizações do terceiro setor, alterando, inclusive, suas próprias identidades e princípios".

Todavia, é possível desenvolver modelos de gestão ajustados aos princípios do terceiro setor, mais voltados ao comprometimento com suas causas (Saraiva, Duarte, de Magalhães, \& Oliveira, 2011). Nesse segmento social, as ações organizacionais são direcionadas a finalidades e a valores, pela sua capacidade de produzirem bens públicos, e com ideais solidários, orientados por uma missão. Essas organizações devem realizar suas atividades com o mínimo de recursos e com os melhores resultados, para o alcance de níveis satisfatórios de eficiência. $\mathrm{O}$ desafio está em adaptar técnicas eficientes de gestão, inerentes ao contexto empresarial, a essas entidades, sem desrespeitar sua lógica de não atuar pelo lucro, mas pela causa (Silva, 2010).

A atuação das entidades do terceiro setor complementa as iniciativas do Estado no atendimento das políticas sociais. A necessidade de serem eficientes, para alcançar sua missão ou se reportar ao governo e aos financiadores, induz ao profissionalismo (Guerra \& Aguiar, 2007), visando suprir a exigência de transparência e a obrigação legal de prestar contas à sociedade, decorrente do aporte de recursos públicos e dos benefícios indiretos auferidos (Borges, 2017).

O cumprimento dos compromissos sociais e a captação de recursos que viabilizem a própria continuidade operacional são as maiores preocupações das organizações do terceiro setor. Em ambientes cada vez mais competitivos, cabe aos doadores a seleção das melhores alternativas para a alocação de recursos. Logo, a credibilidade dessas entidades perante seus mantenedores e demais stakeholders é constantemente avaliada, o que implica na própria sobrevivência (Milani, 2009). É necessário reduzir as dificuldades de gestão ocasionadas pela ausência de pessoal qualificado, falta ou limitação de equipamentos e sistemas de controle, especificidades do setor e obrigação de prestar contas (Arruda, Voese, Espejo, \& Vieira, 2013).

$\mathrm{O}$ processo de gestão requer um conjunto de informações integradas que apoie as decisões em todas as fases, o que permitirá uma maior eficiência organizacional (Cunha, Carpes, \& Utzig, 2014). A contabilidade torna-se relevante na gestão das entidades do terceiro setor por possibilitar, aos gestores e à sociedade, a obtenção de dados que permitem acompanhar os atos e fatos da gestão, além de explicar e predizer situações de natureza econômico-financeira para a devida administração dos recursos públicos, inclusive nos processos de prestação de contas (Borges, 2017). No âmbito gerencial, a contabilidade contempla diversas práticas que podem proporcionar suporte às parcerias no terceiro setor, de forma a tornar transparente e legítima a sua atuação para toda a sociedade, no atendimento dos propósitos para os quais foram constituídas (Arruda $e t$ al., 2013).

Nesse ambiente social encontram-se as fundações sem finalidade lucrativa, constituídas para a prestação de serviços específicos, como as fundações privadas educacionais, de significativa relevância econômico-social como mantenedoras de universidades, as Instituições Comunitárias do Ensino Superior, reconhecidas como agentes propulsores do desenvolvimento regional (Paim, 2017). A intensa participação privada no sistema educacional brasileiro decorre da sua expansão, no nível superior, pela queda das desigualdades de acesso a este nível (Mont’Alvão, 2014).

Do exposto, questiona-se: a implementação das práticas de contabilidade gerencial em uma fundação privada educacional brasileira apoia o alcance da eficiência organizacional? 
Em resposta, este estudo pretende analisar se a implementação das práticas de contabilidade gerencial em uma fundação privada educacional permite alcançar a eficiência organizacional, consideradas as condições e requisitos de entidades integrantes do terceiro setor brasileiro. Essas organizações são desafiadas a alcançar eficiência para atender as demandas técnicas, em prol de sua sustentabilidade, sem deixar de atender às demandas sociais, para concretizar suas missões, por meio da adequação às expectativas da sociedade. Segundo Carvalho (2000), as organizaçóes do terceiro setor posicionam-se "entre a preservação da identidade... com base em valores como a cooperação e a solidariedade e a busca de padrões de eficiência e de eficácia” (p. 1).

Neste estudo entende-se eficiência como o planejamento das atividades organizacionais com otimização de recursos, por meio de práticas de gestão que auxiliem sua realização. Considerando que as organizações do terceiro setor atuam por melhores resultados e para atender expectativas sociais, busca-se o alcance de eficiência e apoio social, de forma a ambos coexistirem.

Em relação às pesquisas nesse segmento social, Hopper e Bui (2016) concluem que um dos principais periódicos científicos de contabilidade gerencial do mundo, o Management Accounting Research (MAR), fez contribuições substanciais para a contabilidade gerencial, nos 25 anos desde o seu lançamento, exceto em áreas críticas, como a do terceiro setor, que foi negligenciada. Embora o terceiro setor receba expressiva atenção de pesquisadores nacionais (Marques, Rody, Campos, \& Reina, 2015), como área de pesquisa dentro da Contabilidade é incipiente e desafiadora, pois há muito o que se pesquisar (Soares, Ramos, Casagrande, \& Nunes, 2019).

Este estudo visa a preencher uma necessidade de pesquisas empíricas que apresentem a contabilidade gerencial como suporte à gestão eficiente das demandas técnicas e sociais de organizações do terceiro setor, com a transposição dos conceitos de gestão tradicionais à realidade desse segmento social, no contexto brasileiro. Como contribuição prática, o estudo demonstra que a implementação das práticas de contabilidade gerencial em organizações do terceiro setor implica no alcance da eficiência organizacional, sem desrespeitar seus princípios norteadores.

\section{Fundamentação Teórica}

\subsection{Contabilidade Gerencial}

A contabilidade gerencial, com o seu propósito de atuar como parceira das organizações na tomada de decisões, contribui na elaboração e implementação das estratégias (IMA, 2008), atende aos interesses dos usuários internos (Guerreiro, Cornachione, \& Soutes, 2011) e possibilita assegurar a sobrevivência da organização, por identificar e analisar seus eventos econômicos e do seu entorno (Atkinson et al., 2015).

As organizações utilizam técnicas de gestão para buscar melhoria de desempenho, pesquisadas e entendidas como práticas de contabilidade gerencial (Russo \& Guerreiro, 2017). Em estudos brasileiros há diferentes termos (Imlau \& Gasparetto, 2017), como artefatos, (Guerreiro et al., 2011; Marassi, Wrubel, \& Rosa, 2014; Oyadomari, Mendonça, Cardoso, \& Lima, 2008; Russo, Parisi, \& Pereira, 2016) para designar o conjunto de instrumentos utilizados pelos profissionais da contabilidade gerencial no exercício de suas funções (Guerreiro et al., 2011). Na literatura internacional predomina o termo management accounting practices (Imlau \& Gasparetto, 2017) para definir o conjunto de instrumentos, métodos, técnicas, ferramentas e filosofias que auxiliam no processo de tomada de decisão e caracterizam as práticas de contabilidade gerencial.

Em sua evolução ao longo do tempo, as práticas de contabilidade gerencial são classificadas como tradicionais e contemporâneas. As tradicionais consideram informações financeiras agregadas, controles operacionais baseados em variações de orçamento padrão e medidas de desempenho, principalmente de natureza financeira, para os sistemas de recompensa; já as contemporâneas contemplam mais medidas de desempenho não financeiras para mensurar o desempenho de empregados em sistemas de recompensa e o valor criado pela organização (Ittner \& Larcker, 1995). Entre as práticas tradicionais estão orçamento, planejamento, medidas de desempenho financeiras, relatórios de resultados por divisão, análise de custos- 
volume-lucro, custo padrão, custeio por absorção e custeio variável; e entre as práticas contemporâneas estão custeio baseado em atividades, gestão baseada em atividades, gestão da qualidade total, kaizen, just in time, valor econômico adicionado, modelo de gestão econômica, gestão baseada em valor, balanced scorecard, custeio meta, medidas de desempenho baseadas em empregados e planejamento estratégico (Chenhall \& Langfield-Smith, 1998).

As práticas de contabilidade gerencial têm sido abordadas em estudos no Brasil e no exterior (Beuren, Rengel, \& Rodrigues, 2015; Frezatti, Barroso, \& Carter, 2015). As pesquisas têm focado no desenvolvimento e na funcionalidade de instrumentos contemporâneos da contabilidade gerencial para apoiar a gestão e a tomada de decisão, bem como nas práticas em uso, e em como ocorre a evolução da contabilidade gerencial nas organizações (Wanderley \& Cullen, 2013). O foco de atuação da contabilidade gerencial e das próprias práticas evoluiu, ao longo do tempo, desde apurar o custo e a lucratividade das operações, ao apoio no planejamento organizacional, gerenciamento de recursos e avaliação de desempenho, tornando-a um importante elemento do controle gerencial para o desenvolvimento de estratégias organizacionais (Atkinson et al., 2015).

Algumas práticas são mais investigadas do que outras. Imlau e Gasparetto (2017) identificaram as 25 práticas de contabilidade gerencial mais abordadas em 20 estudos nacionais e em 17 estudos internacionais, conforme mostra a Tabela 1, em ordem decrescente de citação.

\begin{tabular}{lclc}
\hline Em estudos no Brasil & Quant. & Em estudos internacionais & Quant. \\
\hline Orçamento & 13 & Custo meta & 14 \\
Custeio por absorção & 12 & Custeio baseado atividades & 13 \\
Custeio variável & 12 & Análise custo-volume-lucro & 12 \\
Custo padrão & 11 & Orçamento - planejamento operações anuais & 10 \\
Balanced scorecard (BSC) & 10 & Balanced scorecard (BSC) & 10 \\
Custeio baseado atividades & 10 & Análise lucratividade de produtos & 10 \\
Valor econômico adicionado & 10 & Custos da qualidade & 9 \\
Custo meta (target costing) & 9 & Orçamento de capital & 9 \\
Planejamento estratégico & 8 & Benchmarking & 9 \\
Benchmarking & 8 & Custeio variável & 8 \\
Kaizen & 6 & Orçamento - controle custos & 8 \\
Preço de transferência & 6 & Gestão baseada atividades & 7 \\
Teoria das restrições & 6 & Orçamento - coorden. ativid. interorganizacionais & 7 \\
Fluxo de caixa & 5 & Orçamento de caixa & 7 \\
Moeda constante & 5 & Previsão de longo prazo & 7 \\
Ponto de equilíbrio & 5 & Custeio por absorção & 6 \\
Simulações & 5 & Custo padrão & 6 \\
Valor presente & 5 & Custo de ciclo de vida & 6 \\
Descentralização & 4 & Orçamento - avaliação desempenho gestores & 6 \\
Gestão econômica (Gecon) & 4 & Orçamento baseado em atividades & 6 \\
Just in time & 4 & Análise de variação orçamentária & 6 \\
Resultado unidade de negócios & 3 & Indicadores financeiros & 6 \\
Retorno patrimônio líquido & 3 & Lucro residual & 6 \\
Margem de contribuição & 3 & Valor econômico adicionado & 6 \\
Gestão de estoques & 2 & Análise da lucratividade por cliente & 6 \\
\hline
\end{tabular}

Tabela 1 - Práticas de contabilidade gerencial mais abordadas nos estudos nacionais e internacionais Fonte: Adaptado de Imlau e Gasparetto (2017). Importar tabla

Nas pesquisas internacionais é usual a classificação das práticas nas categorias i) Orçamento, ii) Custos, iii) Informações para tomada de decisão, iv) Avaliação de desempenho e v) Análise estratégica (Imlau \& Gasparetto, 2017). Essa classificação será adotada neste estudo.

\subsection{Gestão do Terceiro Setor Brasileiro: da Filantropia à Gestão Eficiente}

Desde sua origem, o terceiro setor brasileiro veio ampliando seu espaço de atuação, principalmente após a década de 1970, em função das demandas sociais (Silva, 2010). Na década de 1980, um cenário de pressões ambientais e de escassez forçou as organizações do terceiro setor à profissionalização e à busca de alternativas para sua sustentabilidade (Guerra \& Aguiar, 2007). Como parceiras no desenvolvimento social, é essencial profissionalizar a gestão, buscar sustentabilidade financeira, desenvolver conhecimento técnico especializado 
e formar um conjunto menos difuso em relação às formas de atuação dessas organizações (Fischer \& Falconer, 1998).

Nessa evolução, desde o início da década de 1990, mudanças na administração pública brasileira levaram à maior participação das entidades do terceiro setor na formulação e na execução de políticas públicas, com atuação no orçamento público e no rol de programas e ações do governo (Lopez \& Bueno, 2012). A entrada organizada das organizaçóes no setor, por meio do movimento da Responsabilidade Social, veio reforçar a tendência de modernização e de profissionalização dessas organizações, o que delineou a questão da eficiência no setor (Guerra \& Aguiar, 2007).

As práticas de gestão dessas entidades, até então desenvolvidas, foram reforçadas e novas práticas foram introduzidas, como o marketing especializado, a gestão de voluntários e as auditorias externas, levando à formação de profissionais especialistas em "terceiro setor" (Silva, 2010). Há uma tendência de adoção das práticas empresariais para gerir financiamentos, beneficiários e pessoal remunerado ou voluntário, suscitando a necessidade de adaptar conceitos e técnicas de gestão. Assim, as organizações do terceiro setor vêm incorporando práticas advindas da lógica empresarial, como planejamento estratégico, gestão de projetos, finanças, auditoria, accountability, marketing e empowerment (Guerra \& Aguiar, 2007).

No Brasil, a configuração dos aspectos da gestão do terceiro setor ao longo do tempo mostra que o ambiente estabeleceu uma dinâmica que valorizou a orientação instrumental e a atuação profissional neste segmento.

Uma análise histórica sobre os aspectos da gestão no terceiro setor brasileiro, segundo Silva (2010), é ilustrada na Figura 1.

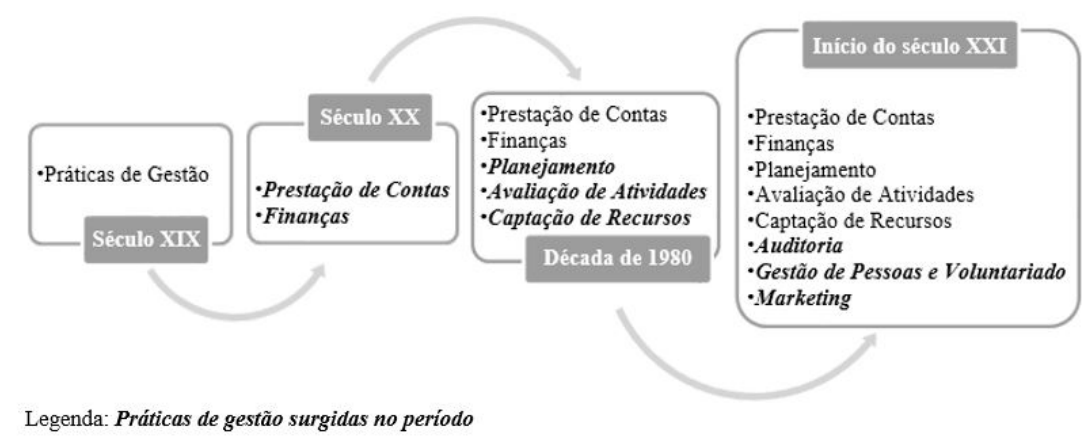

Figura 1 - Configuração dos aspectos da gestão do terceiro setor Fonte: Adaptado de Silva (2010).

As organizações - das filantrópicas às contemporâneas - coexistem num ambiente em que a sobrevivência organizacional passou a vincular-se à adoção de práticas que possibilitem aferir e demonstrar seus níveis de eficiência, eficácia, efetividade e transparência (Silva, 2010).

Cada vez mais, as organizações sem fins lucrativos desenvolvem sistemas de medição de desempenho com métricas de desempenho financeiro focadas também no impacto social, para avaliar o sucesso no cumprimento de suas missões (Epstein \& Mcfarlan, 2011). Conforme Raptopoulos e Silva (2020), as melhores práticas de gestão e de avaliação de desempenho adotadas por entidades do terceiro setor, analisadas num benchmarking internacional, estão relacionadas à mensuração de eficácia e à demonstração dos resultados que impactam em benefícios à sociedade como um todo, para concretizar as missões organizacionais.

No contexto brasileiro, a gestão de uma organização sem fins lucrativos representa o esforço administrativo para um propósito fundamental, seja na execução dos recursos repassados por distintas fontes, seja na prestação de contas à sociedade. Esse esforço contempla a eficiência do trabalho e dos métodos de atuação que 
devem ser aplicados para o alcance da eficiência organizacional, com objetivos, planejamento, organização e controle (Cunha et al., 2014).

\subsection{Estudos Relacionados}

Foram selecionados estudos que apresentam alinhamento com os objetivos deste estudo e contribuem para a elaboração dos constructos da pesquisa.

Os estudos relacionados analisaram a implementação das práticas de contabilidade gerencial em aspectos como o re-design dos processos de negócios e o envolvimento dos contadores (Youssef, 2013), a resistência (Angonese \& Lavarda, 2014), a necessidade de informações de custos no controle gerencial (Marassi et al., 2014), o nível da interação entre regras e rotinas (Oliveira \& Quinn, 2015), a relação entre contradições institucionais, práxis e mudança do controle gerencial (Lavarda \& Popik, 2016) e a lógica institucional cerimonial versus a lógica instrumental (Russo \& Guerreiro, 2017). A evolução da contabilidade gerencial sob pressões ambientais foi explorada nas pesquisas de Oyadomari, Mendonça, Cardoso e Lima (2008) e Lasyoud, Haslam e Roslender (2018). Essas pesquisas evidenciaram que a evolução da contabilidade gerencial está sujeita a pressões econômicas, políticas, culturais e sociais, do ambiente interno e externo, que exercem influência sobre indivíduos e organizações e podem promover ou restringir a implementação das práticas de contabilidade gerencial.

No contexto do terceiro setor foram selecionadas pesquisas publicadas em periódicos internacionais, a partir de 2010. Essas pesquisas analisaram aspectos como uso efetivo ou cerimonial do orçamento (Johanne Pettersen \& Nyland, 2012), uso do orçamento sob pressões externas (Amans, Mazars-Chapelon, \& Villesèque-Dubus, 2015; Ozdil \& Hoque, 2017), adoção de sistemas de contabilidade e controle gerencial (Järvinen, 2016), ideologia organizacional como uma dimensão dos sistemas de controle gerencial (Kraus, Kennergren, \& von Unge, 2017) e o potencial de sistemas de medição de desempenho para expressar valores e crenças organizacionais (Chenhall, Hall, \& Smith, 2017). Os resultados desses estudos trazem uma reflexão sobre o uso cerimonial e instrumental dos sistemas e práticas contábeis gerenciais e circunstâncias nas quais esses usos podem ser complementares.

A existência e a utilização das práticas de contabilidade gerencial em entidades do terceiro setor foram observadas em pesquisas nacionais, como as de Morgan e Benedicto (2009) e de Mário, Alves, Carmo, Silva e Jupetipe (2013), que verificaram o conhecimento e a utilização de instrumentos de contabilidade gerencial por organizações do terceiro setor e as causas da ausência de seu uso. Já Arruda, Voese, Espejo e Vieira (2013) identificaram similaridades entre ferramentas de contabilidade gerencial utilizadas pelo World Wildlife Fund, organização do terceiro setor com sede na Itália e no Brasil, para a gestão da organização. Isidoro, Facci, Espejo e Garcias (2012), Reis e Teixeira (2013) e Imlau e Gasparetto (2017) verificaram a utilização de práticas tradicionais e modernas de contabilidade gerencial em cooperativas agropecuárias, enquanto Lavarda e Popik (2016) analisaram contradições institucionais do controle gerencial e suas implicações, nesse contexto.

Os critérios avaliativos de eficiência em entidades do terceiro setor e os aspectos da gestão econômica sustentável para assegurar o cumprimento da missão da organização e sua continuidade são discutidos nas pesquisas de Valadão, Malaquias e de Sousa (2008), Milani (2009), de Souza, Buffon, Kuss, Flash e Enzweiler (2011), Ribeiro e Timóteo (2012) e de Cunha, Carpes e Utzig (2014). Essas pesquisas foram aplicadas em associações, organizações filantrópicas, entidade religiosa e organizações de sociedade de interesse público (OSCIPs) de microcrédito.

Os resultados dessas pesquisas indicam que, apesar de efetivas melhorias com a utilização de práticas de contabilidade gerencial no apoio à gestão das organizações do terceiro setor, ainda há a necessidade de aprimorar o uso das práticas gerenciais em si. Torna-se vital aperfeiçoar a gestão, seja para atender 
com eficiência as exigências dos financiadores e garantir a captação de recursos, seja para assegurar a sustentabilidade da organização no cumprimento da sua missão.

\section{Procedimentos Metodológicos}

A pesquisa é teórico-empírica, de natureza descritiva, realizada por meio de levantamento, com abordagem qualitativa do problema. A pesquisa foi aplicada em uma fundação privada educacional localizada no Brasil, selecionada pela acessibilidade e por integrar o terceiro setor. A Fundação, instituída na década de 1960, tem relevância econômico-social como mantenedora de uma Instituição Comunitária de Educação Superior (ICES), que atua no desenvolvimento regional interagindo com as comunidades e promovendo o crescimento econômico e social (Paim, 2017).

O processo de transformação em universidade, nos anos 1990, e as exigências do Ministério da Educação, suscitaram a necessidade de ter contabilidade própria na Fundação e de construir o Plano de Desenvolvimento Institucional (PDI), documento de gestão da universidade utilizado em sua avaliação institucional. Apesar de buscar a eficiência econômico-financeira que assegura sua sustentabilidade, a Fundação reverte seu resultado em projetos que beneficiam a comunidade, em função da sua responsabilidade social.

Os dados foram obtidos por meio de documentos disponibilizados pela fundação em seu site e questionário. Os dados documentais orientaram a elaboração do constructo de pesquisa, com relação aos indivíduos envolvidos, a existência de práticas de contabilidade gerencial e os fatores que impulsionaram e (ou) restringiram a implementação e a evolução dessas práticas, na fundação. O questionário segue um roteiro em consonância com os constructos da pesquisa e visa a abranger questões que atendem aos objetivos do estudo, a partir da caracterização do sujeito da pesquisa.

O Bloco A do constructo da pesquisa visa a obter evidências sobre a evolução de práticas de contabilidade gerencial na fundação, por meio dos aspectos pesquisados nos estudos relacionados: (i) implementação das práticas de contabilidade gerencial, (ii) fatores para a mudança e (iii) influência de pressões ambientais. A Tabela 2 apresenta a descrição dos aspectos pesquisados e as referências que fundamentam as questões (Q) dispostas no Bloco A do questionário. 


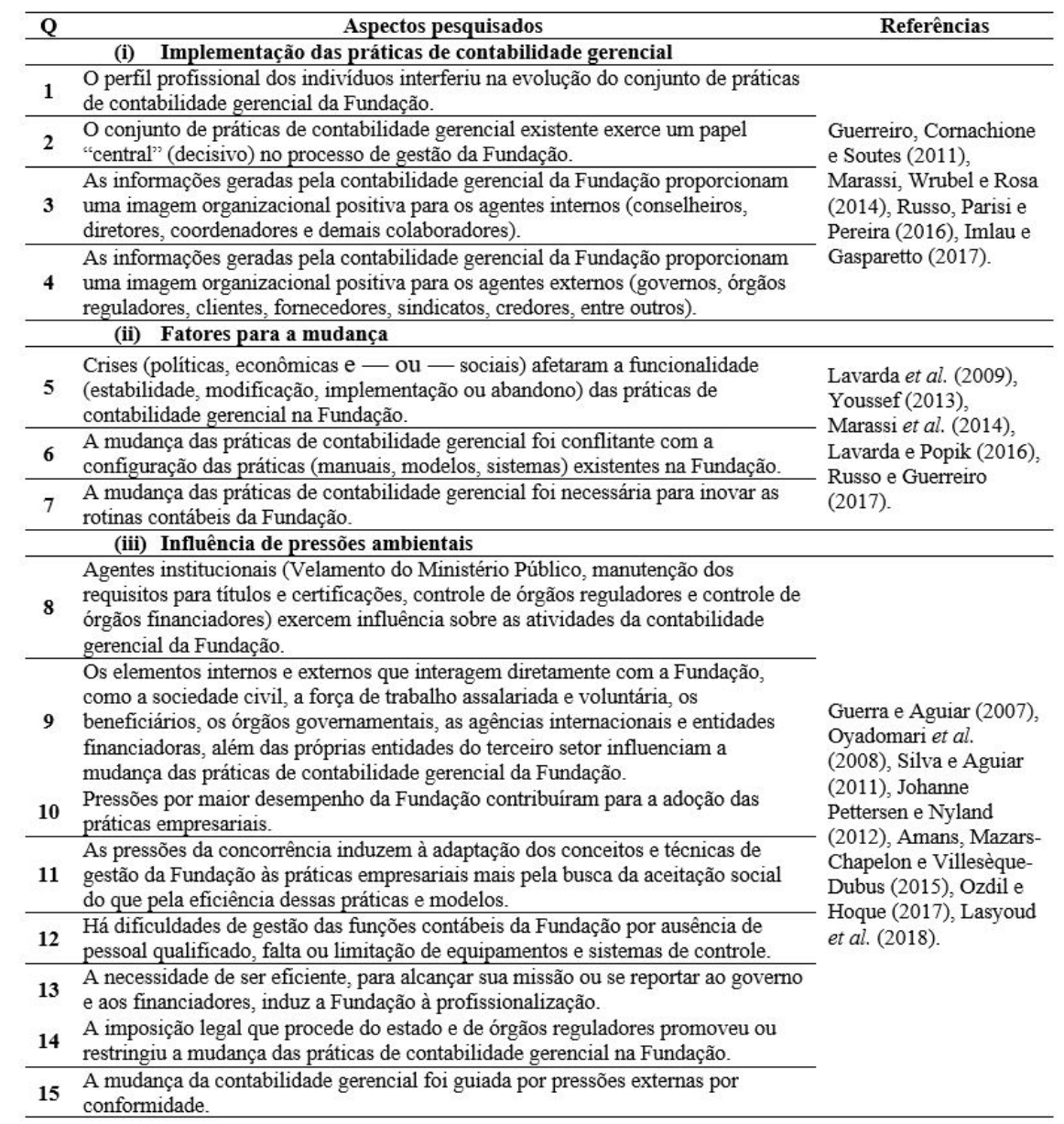

Tabela 2 - Constructo da pesquisa - Bloco A

O Bloco B do constructo da pesquisa visa buscar evidências quanto ao nível de utilização do conjunto de práticas de contabilidade gerencial existentes na fundação, adaptado dos estudos de Guerreiro et al. (2011) e Imlau e Gasparetto (2017). A Tabela 3 apresenta as categorias de práticas e as questões (Q) dispostas no Bloco B do questionário. 


\begin{tabular}{|c|c|c|}
\hline Categorias & $\mathbf{Q}$ & Questões \\
\hline \multirow{2}{*}{ (i) Orçamento } & 16 & Utiliza o orçamento como base para a tomada de decisão. \\
\hline & 17 & Adota práticas de análise de investimentos para o Orçamento de Capital. \\
\hline \multirow{13}{*}{ (ii) Custos } & 18 & Conhece quanto a Fundação precisa "vender" no mês/ano para cobrir gastos fixos. \\
\hline & 19 & $\begin{array}{l}\text { Utiliza o conceito de margem de contribuição (receita menos gastos variáveis) na tomada } \\
\text { de decisão dos gestores. }\end{array}$ \\
\hline & 20 & $\begin{array}{l}\text { Realiza simulações de rentabilidade de produtos (receitas, custos e margem de } \\
\text { contribuição). }\end{array}$ \\
\hline & 21 & Utiliza o custeio baseado em atividades (Activity-Based Costing - ABC). \\
\hline & 22 & Adota a prática de custo meta (Target costing). \\
\hline & 23 & Apura custo dos serviços com base no método de Custeio por Absorção. \\
\hline & 24 & Apura o custo dos serviços com base no método de Custeio Variável. \\
\hline & 25 & Utiliza o Custo Padrão como instrumento de controle de custos. \\
\hline & 26 & $\begin{array}{l}\text { Apura os custos da qualidade (custos de prevenção, de avaliação e de falhas internas e } \\
\text { externas) }\end{array}$ \\
\hline & 27 & $\begin{array}{l}\text { Adota a Gestão Baseada em Atividades (ABM), analisando atividades de baixo valor } \\
\text { agregado para melhorar os processos. }\end{array}$ \\
\hline & 28 & Adota o conceito de Just in time. \\
\hline & 29 & Utiliza a filosofia de melhoria contínua Kaizen. \\
\hline & 30 & $\begin{array}{l}\text { Adota o conceito de Preço de Transferência nos produtos ou serviços destinados a outros } \\
\text { campi. }\end{array}$ \\
\hline \multirow{4}{*}{$\begin{array}{l}\text { iii) Informações } \\
\text { para tomada de } \\
\text { decisão }\end{array}$} & 31 & Compara seus indicadores com os de outras fundações (Benchmarking). \\
\hline & 32 & $\begin{array}{l}\text { Conhece o montante do fluxo de recebimentos e pagamentos esperados para os próximos } \\
\text { meses (fluxo de caixa projetado). }\end{array}$ \\
\hline & 33 & Elabora e analisa relatórios gerenciais em Moeda Constante. \\
\hline & 34 & $\begin{array}{l}\text { Avalia a margem de contribuição por fator limitante de produção com base na Teoria das } \\
\text { Restrições. }\end{array}$ \\
\hline \multirow{4}{*}{$\begin{array}{l}\text { (iv) Avaliação de } \\
\text { desempenho }\end{array}$} & 35 & Conhece a lucratividade por cliente. \\
\hline & 36 & Conhece as sobras (lucratividade) de cada serviço oferecido pela Fundação. \\
\hline & 37 & Adota o sistema de avaliação de desempenho Balanced Scorecard. \\
\hline & 38 & Utiliza o Valor Econômico Adicionado (EVA) para avaliar o desempenho econômico. \\
\hline \multirow{2}{*}{$\begin{array}{l}\text { (v) Análise } \\
\text { estratégica }\end{array}$} & 39 & Elabora o planejamento estratégico. \\
\hline & 40 & Implementa o planejamento estratégico. \\
\hline
\end{tabular}

Tabela 3 - Constructo da pesquisa - Bloco B

O instrumento de pesquisa utilizado é um questionário, estruturado em dois blocos, conforme os constructos da pesquisa, com 40 questões fechadas e tempo de preenchimento estimado em 20 minutos. $\mathrm{O}$ Bloco A tem 15 questões dispostas em escala com 11 opções de respostas, (0) na hipótese de não se aplicar, e as opções de concordância, variando de (1) Discordo Totalmente a (10) Concordo Totalmente, na percepção dos sujeitos da pesquisa. O Bloco B contempla 25 questões. As respostas requeridas são "eu discordo" ou "eu concordo", com relação à intensidade do uso das práticas de contabilidade gerencial na fundação, 0 - hipótese de não utilizar; 1 - pouca intensidade; a 10 - utilização intensa. A escala adotada para classificar os dados, zero - nenhuma concordância, a 10 - total concordância, visa assegurar o rigor metodológico, a exemplo do estudo de Russo e Guerreiro (2017).

Foi efetuada reunião preliminar com o Gerente de Finanças e Contabilidade da Fundação para delinear potenciais sujeitos da pesquisa, agenda para aplicação do questionário e aspectos das práticas de contabilidade gerencial. O questionário foi respondido pelo Gerente, na forma de pré-teste, para garantir clareza e tornálo mais inteligível aos questionados.

O questionário foi aplicado aos responsáveis pela área, colaboradores internos e aos usuários da contabilidade gerencial da Fundação. Esse grupo de respondentes foi escolhido por representar o maior número de usuários do sistema de contabilidade gerencial da Fundação. Em fevereiro de 2019 foram disponibilizados, na sede da Fundação, 42 questionários impressos e recolhidos, posteriormente, 15 com respostas completas. Embora aplicado em 2019, o questionário buscou obter dados sobre práticas de contabilidade gerencial, desde sua implementação na Fundação.

Para verificar a consistência interna das questões do questionário foi realizada análise de confiabilidade com base no Alfa de Cronbach. Segundo Hair, Black, Babin, Anderson e Tatham (2009, p. 126), este indicador varia entre zero e um, com limite inferior recomendado de 0,70 . O resultado obtido para as questóes foi de 0,61, para o Bloco A, de 0,95, para o Bloco B e de 0,88, para o conjunto das questóes. Logo, o questionário pode ser considerado consistente, pois apresenta confiabilidade e coerência interna. 
$\mathrm{Na}$ análise das respostas do questionário foi utilizada estatística descritiva (Lapponi, 2000), para as questões do Bloco A e B. Foi apurada a distribuição de frequência absoluta e relativa, moda e mediana dos resultados do nível de concordância dos respondentes. A análise documental contemplou dados do Balanço Social e Financeiro, Estatuto e PDI, assegurando validade à pesquisa por meio da triangulação de evidências físicas e documentais.

\section{Análise e Discuss ão dos Resultados}

\subsection{Análise Descritiva da Amostra}

A Tabela 4 apresenta as características dos respondentes do questionário.

\begin{tabular}{|c|c|c|c|c|c|}
\hline $\begin{array}{l}\text { Tempo na } \\
\text { Fundação }\end{array}$ & Área de atuação & Cargo Atual & $\begin{array}{c}\text { Tempo no } \\
\text { Cargo }\end{array}$ & Formação Acadêmica & Idade \\
\hline 31 anos & Orçamento & Analista Financeiro & 5 anos & $\begin{array}{l}\text { Ciências Contábeis e } \\
\text { Administração }\end{array}$ & 47 anos \\
\hline 6 anos & Finanças e Contab. & Contador & 5 anos & $\begin{array}{l}\text { Ciências Contábeis, Direito e } \\
\text { MBA em Controladoria }\end{array}$ & 43 anos \\
\hline 14 anos & Finanças e Contab. & Gerente & 7 anos & Economia, Mestrado & 45 anos \\
\hline 8 anos & Finanças e Contab. & Analista Financeiro & 3 anos & Adm. Comércio Exterior & 32 anos \\
\hline 8 anos & Finanças e Contab. & Assistente Financeiro & 3 anos & Economia & 30 anos \\
\hline 9 anos & Finanças e Contab. & Analista Financeiro & 4 anos & Administração & 31 anos \\
\hline 20 anos & Finanças e Contab. & Analista Contábil & - & Ciências Contábeis & 47 anos \\
\hline 25 anos & Finanças e Contab. & Tesoureiro & 25 anos & Ciências Contábeis & 55 anos \\
\hline 37 anos & Biologia & Coordenador de Curso & 1 ano & Ciências Biológicas & 55 anos \\
\hline 17 anos & Letras & Coordenador de Curso & 15 anos & Letras, Mestrado em Educação & 47 anos \\
\hline 6 anos & Economia & Coordenador de Curso & 3 anos & Mestrado & 33 anos \\
\hline 18 anos & Direito & Coordenador de Curso & 2 anos & Direito & 45 anos \\
\hline 20 anos & Fisioterapia & Coordenador de Curso & 3 anos & Doutorado & 49 anos \\
\hline 25 anos & - & Coordenador de Curso & 2 anos & Mestrado & 49 anos \\
\hline 5 anos & Eng. Química & Secretária de Curso & 5 anos & Administração & 35 anos \\
\hline
\end{tabular}

Tabela 4 - Características dos respondentes do questionário

Os respondentes distribuem-se nas faixas de 30 a 55 anos de idade. Observa-se uma concentração quanto à formação e ao tempo de atuação na Fundação. Todos têm curso superior e $40 \%$ são pós-graduados em nível de Especialização, MBA e (ou) Doutorado. Quanto ao tempo de atuação na Fundação, 40\% dos respondentes têm menos de 10 anos.

Em torno de 47\% dos respondentes atuam em cargos de gestão. Cerca de 53,3\% atuam nas áreas de Orçamento, Finanças e Contabilidade, e 46,7\% são usuários do sistema de contabilidade gerencial, com atuação nas grandes áreas do ensino da Fundação, como Sociais Aplicadas, Saúde, Engenharias e Humanas. O perfil desses respondentes permite inferir que possuem aptidão para responder ao questionário.

\subsection{Evolução das práticas de contabilidade gerencial}

\subsubsection{Implementação das práticas de contabilidade gerencial}

A implementação do conjunto das práticas de contabilidade gerencial da Fundação foi promovida pelos seus gestores com o apoio da equipe técnica e de consultores externos.

A Tabela 5 apresenta a estatística descritiva para as questões sobre a implementação das práticas de contabilidade gerencial da Fundação. 


\begin{tabular}{cccccc}
\hline Questões & N. respostas & Mediana & Moda & Mínimo & Máximo \\
\hline Q1 & 15 & 9 & 9 & 7 & 10 \\
Q2 & 15 & 8 & 8 & 5 & 10 \\
Q3 & 15 & 8 & 8 & 8 & 10 \\
Q4 & 15 & 9 & 8 & 7 & 10 \\
\hline
\end{tabular}

Tabela 5 - Estatística descritiva para as questões sobre a implementação das práticas de contabilidade gerencial

O elevado nível de concordância dos respondentes para as questões sobre a implementação das práticas de contabilidade gerencial da Fundação está evidenciado pela moda apurada ( 9 e 8) nas questões 1, 2 e 3.

As frequências absolutas e relativas para o nível de concordância apurado são apresentadas no Apêndice A. As frequências apuradas indicam elevado nível de concordância dos respondentes: o perfil profissional da equipe promoveu a evolução das práticas de contabilidade gerencial (100\%); as práticas de contabilidade gerencial existentes exercem um papel decisivo no processo de gestão da Fundação (93\%) e as informações geradas pelo conjunto de práticas de contabilidade gerencial proporcionam uma imagem organizacional positiva para agentes internos e externos (100\%).

A Figura 2 ilustra o elevado nível de concordância dos respondentes (mais de 98\%) com relação ao conjunto de aspectos que influenciaram a implementação das práticas de contabilidade gerencial.

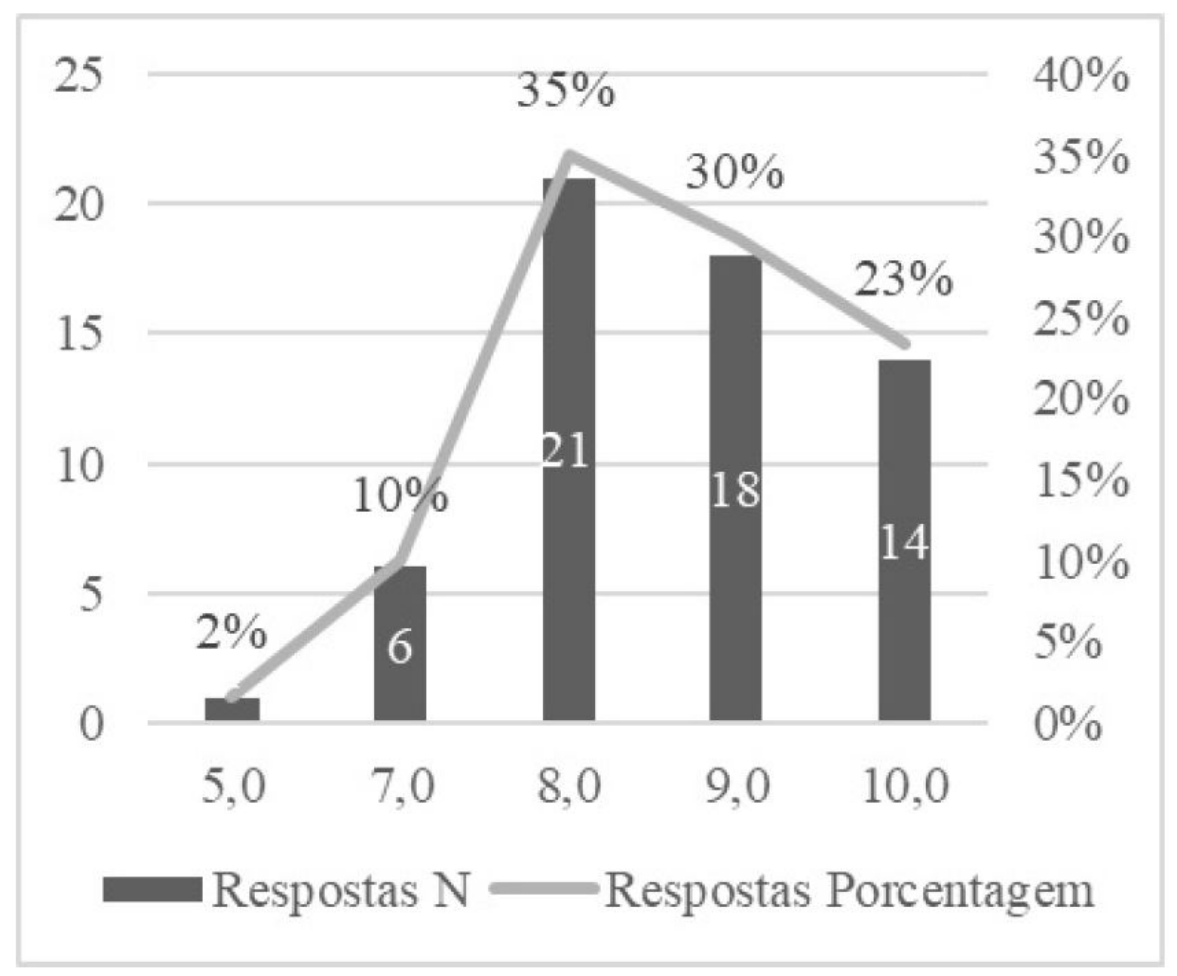

Figura 2 - Frequência do nível de concordância para o conjunto dos aspectos da implementação das práticas de contabilidade gerencial

A estrutura da área de contabilidade da Fundação conta com colaboradores com atribuições diversas na elaboração do conjunto de informações gerenciais. A contratação de pessoal com experiência empresarial suscitou a adoção das práticas empresariais para o acompanhamento de custos e margem de contribuição dos cursos existentes. Consultorias externas influenciaram a implementação de novas práticas e o seu uso na Fundação. As práticas orçamento, margem de contribuição, fluxo de caixa e planejamento estratégico têm um papel decisivo no processo de gestão. A implementação do conjunto das práticas de contabilidade 
gerencial resultou em informações que estão sendo utilizadas pelos usuários, com o acompanhamento da gestão superior.

Esses achados corroboram o estudo de Lavarda e Popik (2016), em que a ineficiência dos controles gerenciais impulsionou a mudança, implementada pela equipe de gestores com auxílio de consultoria especializada. Também nos estudos de Oyadomari et al. (2008), as consultorias exerceram um papel importante na adoção dos artefatos, sendo a decisão da sua escolha prerrogativa dos gestores; nos estudos de Marassi et al. (2014), normas e procedimentos foram idealizados pelos colaboradores e consultores externos, suscitando na aceitação das propostas de mudanças pelos membros da organização.

\subsubsection{Fatores para a mudança}

$\mathrm{Na}$ Fundação, as práticas de contabilidade gerencial foram modificadas e (ou) abandonadas, ao longo do tempo, com a reconfiguração das práticas existentes, pela necessidade de sua inovação.

A Tabela 6 apresenta a estatística descritiva para as questões sobre os fatores para a mudança.

\begin{tabular}{cccccc}
\hline Questões & N. respostas & Mediana & Moda & Mínimo & Máximo \\
\hline Q5 & 15 & 8 & 8 & 0 & 10 \\
Q6 & 15 & 8 & 8 & 0 & 10 \\
Q7 & 14 & 9 & 9 & 0 & 10 \\
\hline
\end{tabular}

Tabela 6 - Estatística descritiva para as questões sobre os fatores para a mudança

O elevado nível de concordância dos respondentes, para as questões com relação aos fatores para a mudança analisados, está evidenciado pela moda apurada (8 e 9) nas questões 5, 6 e 7.

As frequências absolutas e relativas para o nível de concordância apurado são apresentadas no Apêndice A. As frequências apuradas indicam elevado nível de concordância dos respondentes (mais de 70\%) com relação ao conjunto dos fatores que influenciaram a mudança das práticas de contabilidade gerencial.

A inovação das práticas de contabilidade gerencial decorreu de readaptação e orientação da equipe na elaboração da proposta orçamentária anual, exigida por lei, e de integração de sistemas para o acompanhamento dos resultados de cada centro de custos, além do organizacional, pelos gestores responsáveis. As mudanças ocorreram com a interrupção substancial da configuração das práticas existentes, no início do processo, quando houve uma ruptura na forma de elaborar, implementar e justificar a proposta orçamentária em função de sua descentralização.

A Figura 3 ilustra o elevado nível de concordância dos respondentes (mais de 70\%) com relação ao conjunto dos fatores para a mudança das práticas de contabilidade gerencial. 


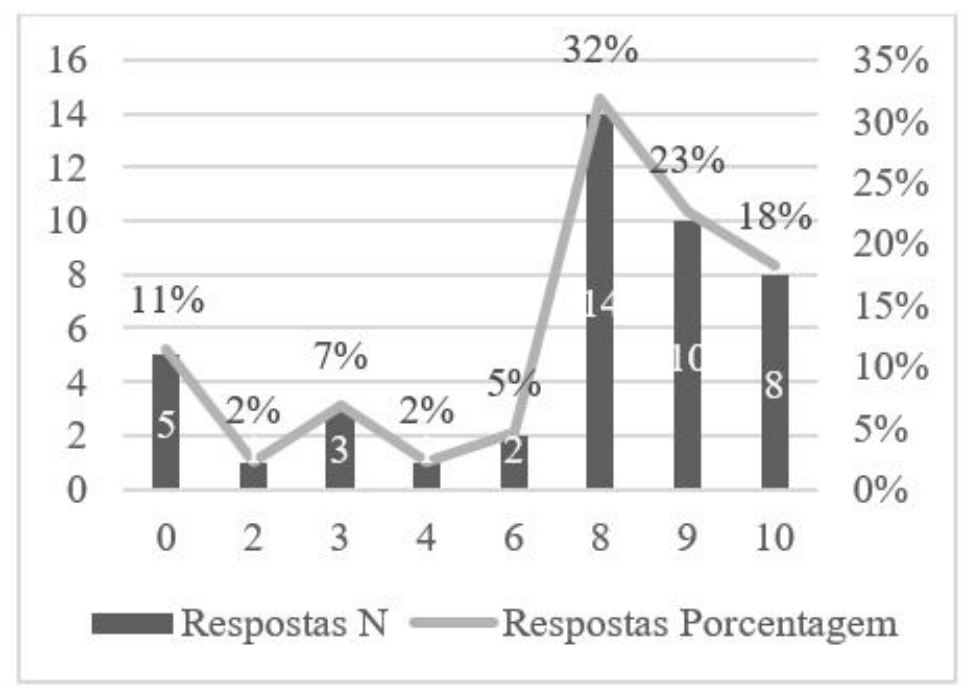

Figura 3 - Frequência do nível de concordância para o conjunto dos fatores para a mudança

As resistências advindas da implementação do processo orçamentário descentralizado foram superadas e não tiveram forças suficientes para restringir a mudança. Essa resistência foi reduzida em razão do planejamento dos gestores e do comprometimento dos colaboradores da Fundação, a exemplo do estudo de Angonese e Lavarda (2014), em que a bem-sucedida implementação da mudança decorreu das estratégias empregadas pela gestão para mitigar os fatores de resistência.

Esses resultados mostram a evolução da contabilidade gerencial na Fundação. As práticas de gestão existentes foram reforçadas e novas foram introduzidas, compondo o conjunto de práticas de contabilidade gerencial da Fundação, como orçamento, margem de contribuição por centro de custo, fluxo de caixa, planejamento estratégico, viabilidade econômica e ponto de equilíbrio dos cursos, informaçóes estatísticas, mapeamento docente e PDI.

\subsubsection{Influência de pressões ambientais}

Por integrar o terceiro setor, a Fundação vem respondendo às pressões e forças ambientais que estabelecem critérios mais rígidos para as operações e resultados alcançados, com exigência de eficiência organizacional. $\mathrm{Na}$ Fundação, as mudanças das práticas de contabilidade gerencial ocorreram em resposta às pressões do estado, de redes profissionais e de órgãos reguladores. Esse processo suscitou o atendimento das pressões ambientais, por meio da adequação organizacional aos valores desse segmento social.

A Tabela 7 apresenta a estatística descritiva para as questões com relação à influência das pressões ambientais sobre a mudança das práticas de contabilidade gerencial da Fundação. 


\begin{tabular}{cccccc}
\hline Questões & N. respostas & Mediana & Moda & Mínimo & Máximo \\
\hline Q8 & 15 & 9 & 9 & 0 & 10 \\
Q9 & 15 & 8 & 9 & 0 & 10 \\
Q10 & 15 & 7 & 9 & 0 & 10 \\
Q11 & 15 & 5 & 0 & 0 & 10 \\
Q12 & 15 & 2 & 0 & 0 & 10 \\
Q13 & 13 & 10 & 10 & 8 & 10 \\
Q14 & 15 & 9 & 10 & 0 & 10 \\
Q15 & 14 & 4 & 0 & 0 & 10 \\
\hline
\end{tabular}

Tabela 7 - Estatística descritiva para as questões sobre a influência das pressões ambientais

O elevado nível de concordância dos respondentes, para as questões com relação à influência das pressões ambientais, está evidenciado pela moda apurada ( 9 e 10) nas questões 8, 9, 10, 13 e 14. Não houve concordância para as questões 11,12 e 15 (moda 0$)$.

As frequências absolutas e relativas para o nível de concordância apurado são apresentadas no Apêndice A. As frequências apuradas indicam elevado nível de concordância dos respondentes (mais de 90\%) com relação às pressões ambientais. A mudança das práticas de contabilidade gerencial da Fundação foi influenciada pelos elementos internos e externos que interagem diretamente com a Fundação (80\%); pressões por maior desempenho contribuíram para a adoção das práticas empresariais (mais de 70\%). Contudo, mais de 53\% dos respondentes discordaram de que as pressões da concorrência tenham induzido à adaptação dos conceitos e técnicas de gestão à lógica empresarial, mais pela aceitação social do que pela sua eficiência.

Embora a Fundação busque eficiência econômico-financeira, foram obtidas evidências complementares, no Balanço Financeiro de 2005 a 2018, que revelam resultados deficitários em seis exercícios financeiros dentro do período analisado. A lógica da Fundação é reinvestir o resultado em benefícios sociais, como a oferta de cursos de licenciatura, por meio de incentivos públicos, assegurando a existência de professores no futuro, apesar dos históricos déficits nas quatro áreas do ensino.

Conforme $60 \%$ dos respondentes, não há dificuldades de gestão das funções contábeis da Fundação por ausência de pessoal qualificado e de falta ou limitação de equipamentos e sistemas de controle. Todos concordam que a profissionalização da equipe decorreu da necessidade de eficiência. A Fundação participa de uma Associação de Fundações Educacionais, que orienta suas associadas a adotarem estratégias similares, resultando numa padronização de estruturas organizacionais.

A existência de regras, leis e sanções, a forma jurídica de Fundação, os títulos e certificações concedidos pelo poder público, os conselhos de políticas públicas e os financiadores influenciaram a mudança das práticas de contabilidade gerencial da Fundação (concordância de mais de $70 \%$ dos respondentes). Cerca de 57\% dos respondentes discordaram de que essa mudança tenha sido guiada por pressões externas por conformidade.

A Figura 4 ilustra o elevado nível de concordância dos respondentes (mais de 60\%) com relação ao conjunto das pressões ambientais que exerceram influência sobre a mudança das práticas de contabilidade gerencial 


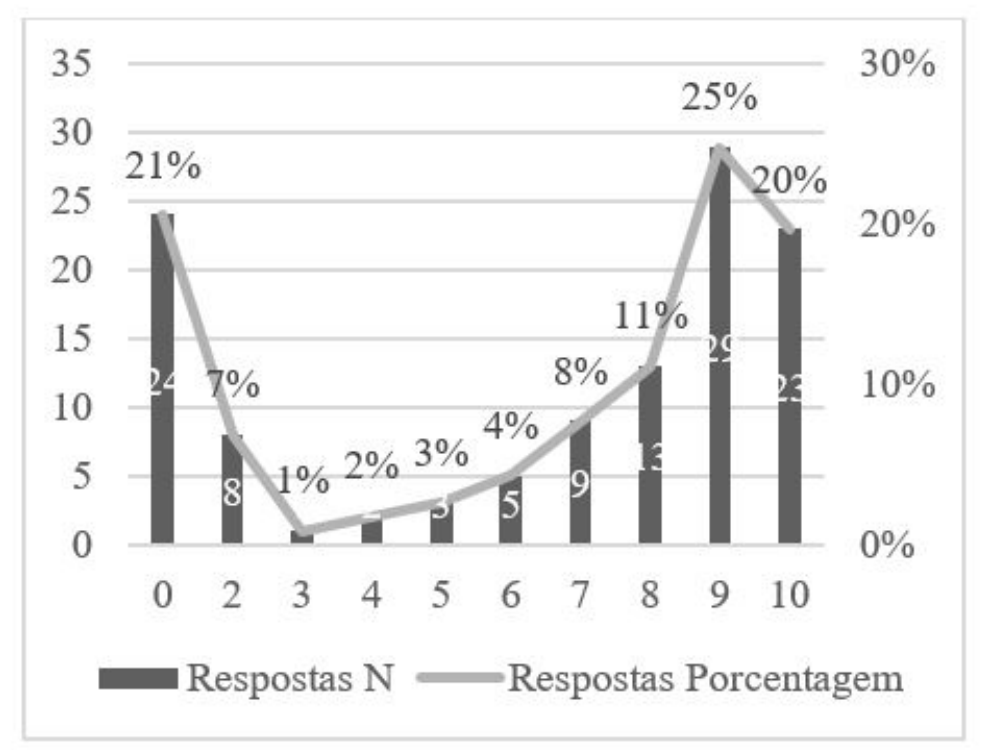

Figura 4 - Frequência do nível de concordância para o conjunto das pressões ambientais

As frequências apuradas indicam elevado nível de concordância dos respondentes com relação à influência exercida pelos agentes institucionais, pelos elementos internos e externos, por maior desempenho e eficiência e por imposição legal sobre a mudança das práticas de contabilidade gerencial. Não houve concordância significativa com relação às pressões da concorrência, por conformidade externa e por dificuldades de gestão das funções contábeis.

\subsection{Utilização das práticas de contabilidade gerencial}

A Tabela 8 apresenta a estatística descritiva para as questões sobre o nível de utilização das práticas de contabilidade gerencial existentes na Fundação. 


\begin{tabular}{cccccc}
\hline Questões & N. respostas & Mediana & Moda & Mínimo & Máximo \\
\hline Q16 & 15 & 9 & 10 & 7 & 10 \\
Q17 & 13 & 7 & 0 & 0 & 10 \\
Q18 & 15 & 9 & 10 & 5 & 10 \\
Q19 & 15 & 9 & 10 & 7 & 10 \\
Q20 & 15 & 9 & 9 & 0 & 10 \\
Q21 & 13 & 0 & 0 & 0 & 10 \\
Q22 & 14 & 0 & 0 & 0 & 10 \\
Q23 & 13 & 0 & 0 & 0 & 10 \\
Q24 & 12 & 0 & 0 & 0 & 10 \\
Q25 & 12 & 0 & 0 & 0 & 10 \\
Q26 & 13 & 0 & 0 & 0 & 10 \\
Q27 & 12 & 0 & 0 & 0 & 10 \\
Q28 & 12 & 0 & 0 & 0 & 10 \\
Q29 & 14 & 0 & 0 & 0 & 10 \\
Q30 & 14 & 0 & 0 & 0 & 10 \\
Q31 & 15 & 0 & 0 & 0 & 10 \\
Q32 & 14 & 9,5 & 10 & 0 & 10 \\
Q33 & 14 & 9 & 10 & 0 & 10 \\
Q34 & 13 & 0 & 0 & 0 & 10 \\
Q35 & 13 & 5 & 0 & 0 & 10 \\
Q36 & 14 & 9 & 10 & 0 & 10 \\
Q37 & 13 & 0 & 0 & 0 & 10 \\
Q38 & 13 & 0 & 0 & 0 & 10 \\
Q39 & 15 & 9 & 10 & 0 & 10 \\
Q40 & 15 & 9 & 10 & 0 & 10 \\
\hline
\end{tabular}

Tabela 8 - Estatística descritiva para as questóes sobre o nível de utilização das práticas de contabilidade gerencial

Conforme a moda apurada (9 e 10), houve elevado nível de concordância dos respondentes quanto a conhecer e (ou) utilizar as práticas orçamento, custo-volume-lucro, margem de contribuição, rentabilidade de produtos, fluxo de caixa projetado, lucratividade por produto, relatórios gerenciais em moeda constante e planejamento estratégico. Não houve concordância quanto ao uso das demais práticas analisadas (moda 0 ).

Essas evidências mostram que são conhecidas e utilizadas, na Fundação, menos da metade das 25 principais práticas mais abordadas na literatura, as quais podem não refletir a realidade das práticas de gestão de organizações do terceiro setor brasileiras, dada a complexidade de que se reveste esse ambiente. Ao que parece, a utilização das práticas de contabilidade gerencial não é suportada pelo simples fato de que são úteis ao processo de decisão, o que contraria os achados de Arruda et al. (2013), que identificaram similaridades nas práticas de contabilidade gerencial utilizadas pelo World Wildlife Fund para a gestão organizacional na Itália e no Brasil.

A frequência absoluta e relativa para o nível de concordância apurado é apresentada no Apêndice B. As frequências apuradas mostram que as práticas da categoria custos, como custeio baseado em atividades, custo meta, custeio por absorção, custeio variável, custo padrão, custos da qualidade, gestão baseada em atividades, Just in time, melhoria contínua Kaizen e preço de transferência não são conhecidas e (ou) utilizadas, na Fundação, por cerca de $64 \%$ a $93 \%$ dos respondentes. Na categoria informações para tomada de decisão, as práticas Benchmarking e teoria das restrições são desconhecidas por $60 \%$ e $77 \%$ dos respondentes, respectivamente, condizente com a literatura consultada.

$\mathrm{Na}$ categoria avaliação de desempenho, as práticas lucratividade por cliente, Balanced Scorecard e valor econômico adicionado são desconhecidas por cerca de 54\%, 85\% e 69\% dos respondentes, respectivamente. Segundo Guerreiro et al. (2011), a intensidade da utilização varia de artefato para artefato e que mesmo artefatos com menor uso, como Just in time, Kaizen e Target costing foram empregados por mais de 30\% das empresas estudadas. 
As categorias de práticas custos, informações para tomada de decisão e avaliação de desempenho apresentam os níveis de discordância mais altos (cerca de 60\%, 50\% e 57\%), quanto à utilização do conjunto das práticas analisadas, conforme ilustra a Figura 5. Todavia, para as categorias informações para tomada de decisão e avaliação de desempenho, são conhecidas e (ou) utilizadas as práticas fluxo de caixa, moeda constante e lucratividade por produto, na percepção de mais de 71\%, 64\% e 78\% dos respondentes, respectivamente.
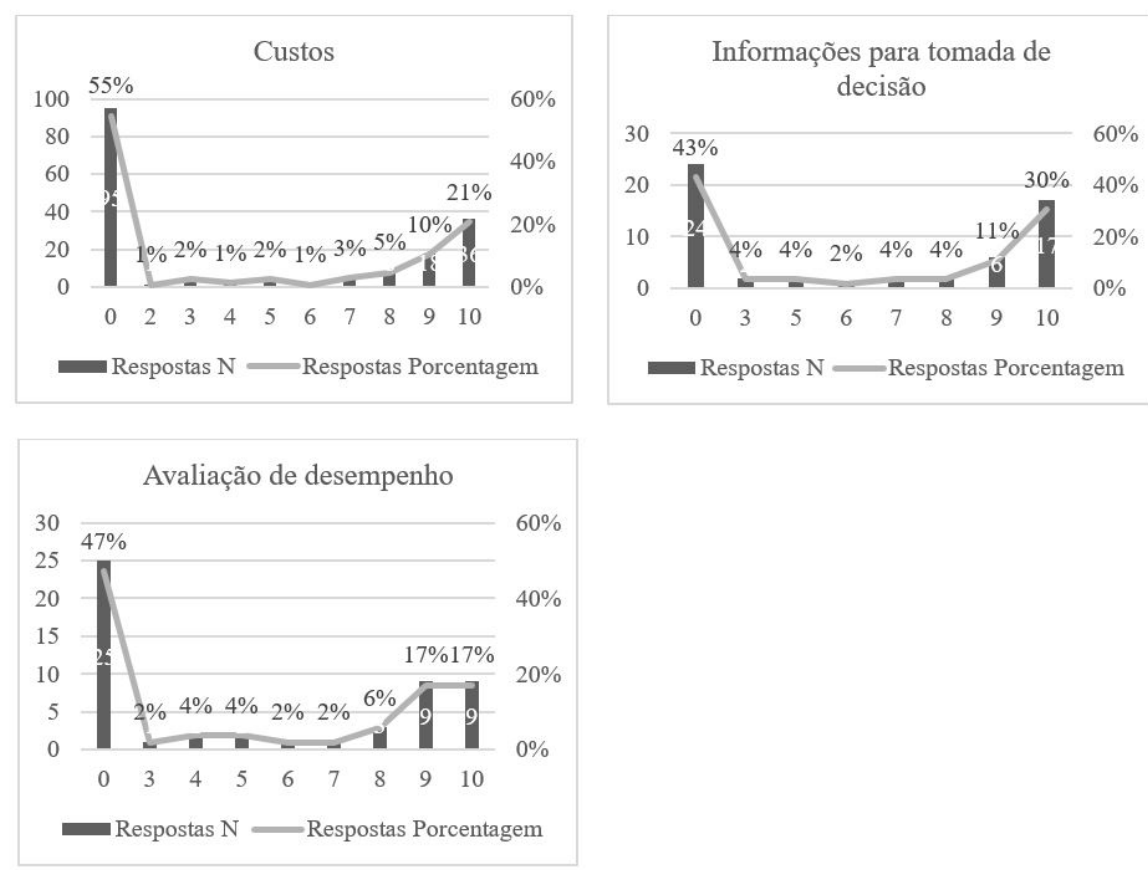

Figura 5 - Frequência do nível de discordância quanto ao uso do conjunto das práticas das categorias custos, informações para tomada de decisão e avaliação de desempenho

Foi verificada a correlação entre as práticas com o tempo na Fundação e no cargo (Apêndice C). A mediana do tempo de atuação na Fundação é de 17 anos e do tempo no cargo, de 3,5 anos. Para o tempo de Fundação e o tempo de atuação nos cargos não houve correlações positivas significativas entre si. As mais fortes correlações, de 0,02 a 0,57 , foram entre cargo de atuação e as práticas da categoria custos, na qual $60 \%$ dos respondentes informou desconhecer e (ou) não utilizar. A correlação mais fraca $(0,02)$ deu-se com a prática kaizen.

Era esperado que a atuação em áreas distintas da contabilidade refletisse conhecimento deficiente das práticas, ou das suas terminologias, induzindo à interpretação inadequada das afirmativas, apesar do elevado tempo de cada respondente na Fundação. Todavia, a atuação dos usuários da contabilidade gerencial, em cargos específicos da área de finanças e das distintas áreas de ensino, não parece exercer influência sobre o nível de utilização das práticas de contabilidade gerencial da Fundação. Essa evidência contrapõe o estudo de Russo et al. (2016), em que a influência da heterogeneidade dos indivíduos usuários das práticas de contabilidade gerencial levou a prática a ser mais conhecida e utilizada.

Os achados permitem concluir que as práticas de contabilidade gerencial relacionadas a orçamento, margem de contribuição, fluxo de caixa, avaliação de desempenho e planejamento estratégico são efetivamente conhecidas e utilizadas na Fundação, para apoiar a tomada de decisão, refletindo maior uso das práticas tradicionais de contabilidade gerencial. Esses achados corroboram os estudos de Oyadomari et al. (2008), Guerreiro et al. (2011), Isidoro et al. (2012), Reis e Teixeira (2013) e Imlau e Gasparetto (2017), que identificaram maior nível de adoção de práticas tradicionais de contabilidade gerencial frente às modernas.

Contudo, esses resultados contrapõem os estudos de Mário et al. (2013), que perceberam a ausência de uso de práticas de contabilidade gerencial, em razão da indisponibilidade de recursos financeiros e da falta 
de conhecimento sobre os instrumentos gerenciais, e de Morgan e Benedicto (2009), que observaram a utilização de informações para tomada de decisão, porém, advindas da contabilidade financeira.

\section{Considerações Finais}

O presente estudo analisou se a implementação de práticas de contabilidade gerencial em uma fundação privada educacional contribui para o alcance da eficiência organizacional, consideradas as especificidades do terceiro setor brasileiro.

A implementação das práticas de contabilidade gerencial na Fundação vem ocorrendo ao longo de seus mais de 50 anos de atividades, motivada pela necessidade da gestão de ter ferramentas mais ágeis e seguras para apoiar a tomada de decisão.

Condizente com a literatura, distintas pressões influenciaram a mudança das práticas de contabilidade gerencial da Fundação, como as advindas do Estado, de redes profissionais e de órgãos reguladores. Os gestores tendem a adotar estratégias das entidades concorrentes, num esforço coletivo de incorporar técnicas eficazes para alcançar padrões de profissionalismo, pela necessidade de eficiência da Fundação e para alcançar sua missão.

Em razão do segmento social no qual está inserida a Fundação, a implementação das práticas de contabilidade gerencial foi orientada por eficiência organizacional, para o atendimento das demandas técnicas da Fundação - em prol de sua sustentabilidade financeira, e das demandas sociais - para concretizar sua missão, no atendimento das expectativas da sociedade.

$\mathrm{Na}$ Fundação, a geração de informações para apoio à gestão está sedimentada, principalmente a cultura orçamentária, de fluxo de caixa e de análise de custos dos cursos novos e em andamento, para verificar sua viabilidade econômica. As práticas tradicionais de contabilidade gerencial relacionadas a orçamento, margem de contribuição, fluxo de caixa e planejamento estratégico são efetivamente conhecidas e utilizadas e têm um papel decisivo no processo de gestão, contribuindo para o alcance da eficiência organizacional.

O estudo contribui para a literatura contábil por apresentar evidências do campo empírico sobre a implementação de práticas de contabilidade gerencial em organizações do terceiro setor, e suas implicações nesse segmento social. A contribuição prática consiste em demonstrar a gestores e consultores o processo de implementação das práticas de contabilidade gerencial em organizações sem fins lucrativos, para o alcance da eficiência organizacional, por evidenciar relevantes pressões ambientais que podem promover ou restringir a evolução das práticas de contabilidade gerencial.

Em continuidade à pesquisa, sugere-se explorar os aspectos da gestão no terceiro setor. As evidências do caso revelam a existência de conflitos decorrentes de distintas lógicas de gestão, fundamentadas na lógica institucional cerimonial (baseada em ritos) versus a lógica instrumental (baseada na resolução de problemas), como propõem Russo e Guerreiro (2017).

As limitações deste trabalho sinalizam oportunidades para estudos futuros. A coleta de dados por meio de documentos e questionário e a reduzida quantidade de respostas podem afetar a compreensão de todos os aspectos do fenômeno. $\mathrm{O}$ recorte temporal do estudo induz os respondentes a respostas distintas da realidade. Métodos alternativos podem ser adotados para obter dados mais adequados ao constructo da pesquisa.

Recomenda-se a replicação da pesquisa em outras organizações sem fins lucrativos para aumentar a validade do constructo teórico-metodológico proposto e possibilitar o cotejamento dos resultados por meio da generalização teórica, o que sinaliza estudos de casos múltiplos dentro de uma mesma área de atuação ou em áreas específicas do terceiro setor. 


\section{REFERÊNCIAS}

Amans, P., Mazars-Chapelon, A., \& Villesèque-Dubus, F. (2015). Budgeting in institutional complexity: The case of performing arts organizations. Management Accounting Research, 27, pp. 47-66. https://doi.org/10.1016/j.ma r.2015.03.001

Angonese, R., \& Lavarda, C. E. F. (2014). Analysis of the factors affecting resistance to changes in management accounting systems. Revista Contabilidade \& Finanças, 25(66), pp. 214-227. https://dx.doi.org/10.1590/1808 $-057 \times 201410810$

Arruda, L. L., Voese, S. B., Espejo, M. M. dos S. B., \& Vieira, F. G. D. (2013). Ferramentas de contabilidade gerencial no terceiro setor: um estudo comparativo entre as WWF Brasil e Itália. Revista Iberoamericana de Contabilidad de Gestión, 11(22), pp. 1-21.

Atkinson et al. (2015). Contabilidade Gerencial. São Paulo: Atlas.

Beuren, I. M., Rengel, S., \& Rodrigues, M. M. Junior (2015). Relação dos atributos da contabilidade gerencial com os estágios do ciclo de vida organizacional. Innovar, 25(57), pp. 63-78. http://dx.doi.org/10.15446/innovar.v2 $5 n 57.50328$

Borges, G. M. C. (2017). Determinantes dos impedimentos de concessöes e transferências de recursos públicos às entidades privadas sem fins lucrativos no Brasil (Tese de doutorado). Universidade de Brasília, Universidade Federal da Paraíba, Universidade Federal do Rio Grande do Norte, Natal, RN, Brasil. http://repositorio.unb.br/handle/ $10482 / 22366$

Carvalho, C. A. P. D. (2000). Preservar a identidade e buscar padrões de eficiência: questões complementares ou contraditórias na atualidade das organizaçôes não governamentais? REAd-Revista Eletrônica de Administração, 6(2), pp. 1-21. http://hdl.handle.net/10183/19413

Chenhall, R. H., \& Langfield-Smith, K. (1998). The relationship between strategic priorities, management techniques and management accounting: an empirical investigation using a systems approach. Accounting, Organizations and Society, 23(3), pp. 243-264. https://doi.org/10.1016/S0361-3682(97)00024-X

Chenhall, R. H., Hall, M., \& Smith, D. (2017). The expressive role of performance measurement systems: A field study of a mental health development project. Accounting, Organizations and Society, 63, pp. 60-75. https://doi.org/ 10.1016/j.aos.2014.11.002

Cunha, P. R. da, Carpes, A. M. da S., \& Utzig, M. J. S. (2014). Gestão e desempenho em organizações de sociedade de interesse público (OSCIPs): um estudo em entidades de microcrédito. Revista Ambiente Contábil, 6(1), pp. 202-218. https://periodicos.ufrn.br/ambiente/article/view/4127

de Souza, M. A., Buffon, B., Kuss, I. R., Flash, C. J., \& Enzweiler, M. A. (2011). Gestão sustentável de instituição assistencial religiosa: um estudo na Província São Francisco de Assis (PSFA). ConTexto, 11(20), pp. 45-57. htt ps://www.seer.ufrgs.br/ConTexto/article/view/22428

Epstein, M.J., \& McFarlan, F. (2011). Measuring the efficiency and effectiveness of a nonprofit's performance. Strategic Finance, 93, pp. 27-35. https://www.semanticscholar.org/paper/Measuring-the-efficiency-and-effectiveness-of -a-Epstein-McFarlan/5b128b296883a427c19f5b1d22ea22bad4dfc270

Fischer, R. M., \& Falconer, A. P. (1998). Desafios da parceria governo e terceiro setor. Revista de administração, 33(1), pp. 12-19. http://www.spell.org.br/documentos/ver/18151/desafios-da-parceria-governo-no-terceiro-setor

Frezatti, F., Barroso, M. F. G., \& Carter, D. B. (2015). Discursos internos se sustentam sem suporte da contabilidade gerencial? Um estudo de caso no setor de autopeças. Organizações \& Sociedade, 22(75), pp. 485-503. http://w ww.redalyc.org/articulo.oa?id=400641525002

Guerra, C. E., \& Aguiar, A. C. (2007). Institucionalização do terceiro setor brasileiro: da filantropia à gestão eficiente. In Congresso Virtual Brasileiro de Administração (Vol. 4, pp. 1-18). http://www.convibra.com/2007/congress o/artigos/188.pdf

Guerreiro, R., Cornachione, E. B. Júnior, \& Soutes, D. O. (2011). Empresas que se destacam pela qualidade das informações a seus usuários externos também se destacam pela utilização de artefatos modernos de contabilidade 
gerencial? Revista Contabilidade \& Finanças, 22(55), pp. 88-113. https://doi.org/10.1590/S1519-707720110 00100006

Hair, J. F., Black, W. C., Babin, B. J., Anderson, R. E., \& Tatham, R. L. (2009). Análise multivariada de dados. São Paulo: Bookman Editora.

Hopper, T., \& Bui, B. (2016). Has management accounting research been critical? Management Accounting Research, 31, pp. 10-30. https://doi.org/10.1016/j.mar.2015.08.001

Imlau, J. M.; Gasparetto, V. (2017). Práticas de contabilidade gerencial em cooperativas de produção agropecuária do estado do Rio Grande do Sul. Custos e @gronegócio on line, 13(2),pp. 237-264. http://www.custoseagronegoci oonline.com.br/numero2v13/OK\%2013\%20gerencial.pdf

Institute of management accountants. (1998). Definition of management accounting. IMA.

Isidoro, C., Facci, N., Espejo, M. M. D. S. B., \& Garcias, P. M. (2012). A utilização de artefatos de contabilidade gerencial em cooperativas agropecuárias. Revista de Contabilidade da UFBA, 6(2), pp. 39-55. https://portalsee r.ufba.br/index.php/rcontabilidade/article/view/5948

Ittner, C. D., \& Larcker, D. F. (1995). Total quality management and the choice of information and reward systems. Journal of Accounting Research, 33, pp. 1-34. DOI: 10.2307/2491371 https://www.jstor.org/stable/2491371

Järvinen, J. T. (2016). Role of management accounting in applying new institutional logics: A comparative case study in the non-profit sector. Accounting, Auditing \& Accountability Journal, 29(5), pp. 861-886. https://doi.org/1 0.1108/AAAJ-07-2012-01058

Johanne Pettersen, I., \& Nyland, K. (2012). Reforms and clinical managers' responses: a study in Norwegian hospitals. Journal of Health Organization and Management, 26(1), pp. 15-31. https://doi.org/10.1108/1477726121121 1070

Kraus, K., Kennergren, C., \& von Unge, A. (2017). The interplay between ideological control and formal management control systems - A case study of a non-governmental organisation. Accounting, Organizations and Society, 63, pp. 42-59. https://doi.org/10.1016/j.aos.2016.02.001

Lapponi, J. (2000). Estatistica usando Excel. São Paulo: Elsevier.

Lasyoud, A. A., Haslam, J., \& Roslender, R. (2018). Management accounting change in developing countries: evidence from Libya. Asian Review of Accounting, 26(3), pp. 278-313. https://doi.org/10.1108/ARA-03-2017-0057

Lavarda, C. E. F., \& Popik, F. (2016). Contradições institucionais, práxis e mudança do controle gerencial: Estudo de caso em uma cooperativa. Advances in Scientific and Applied Accounting, 9(2), pp. 119-140. http://asaa.anpcon t.org.br/index.php/asaa/article/view/240/159

Lopez, F., \& Bueno, N. (2012). Transferências federais a entidades privadas sem fins lucrativos (1999-2010). http://h dl.handle.net/10419/91131

Marassi, R. B., Wrubel, F., \& Rosa, F. S. D. (2014). Análise da Institucionalização de Artefatos de Custos no Controle Gerencial em uma empresa Têxtil. Sociedade, Contabilidade e Gestão, 9(2), pp. 58-79. http://atena.org.br/revi sta/ojs-2.2.3-06/index.php/ufrj/article/viewArticle/2259

Mário, P. D. C., Alves, A. D. D. F., Carmo, J. P. S. D., Silva, A. P. B. D., \& Jupetipe, F. K. N. (2013). A utilização de instrumentos de contabilidade gerencial em entidades do terceiro setor. Sociedade, Contabilidade e Gestão, 8(1), pp. 64-79. https://doi.org/10.21446/scg_ufrj.v8i1.13283

Marques, B. A., Rody, P. H. A., Campos, G. M., \& Reina, D. (2015). Terceiro Setor: panorama das tendências de 1998 a 2013 por meio de um estudo bibliométrico. Enfoque: Reflexão Contábil, 34(2), pp. 71- 89. http://periodicos. uem.br/ojs/index.php/Enfoque/article/view/23439

Milani Filho, M. A. F. (2009). Resultado econômico em organizações do Terceiro Setor: um estudo exploratório sobre a avaliação de desempenho. Revista Contabilidade e Controladoria, 1(1), pp. 35-44. http://dx.doi.org/10.5380 /rcc.v1i1.14710

Mont'Alvão, A. L. Neto (2014). Tendências das desigualdades de acesso ao ensino superior no Brasil: 1982-2010. Educação \& Sociedade, 35(127), pp. 417-441. https://doi.org/10.1590/S0101-73302014000200005 
Morgan, L. M., \& de Benedicto, G. C. (2009). Um estudo sobre a controladoria em organizações do terceiro setor na Região Metropolitana de Campinas. Revista de Administração, 7(3), pp. 111-133.

Oliveira, J., \& Quinn, M. (2015). Interactions of rules and routines: re-thinking rules. Journal of Accounting \& Organizational Change, 11(4), 503-526. https://doi.org/10.1108/JAOC-11-2013-0095

Oyadomari, J. C., de Mendonça, O. R. Neto, Cardoso, R. L., \& de Lima, M. P. (2008). Fatores que influenciam a adoção de artefatos de controle gerencial nas empresas brasileiras: um estudo exploratório sob a ótica da teoria institucional. Revista de Contabilidade e Organizações, 2(2), pp. 55-70. https://doi.org/10.11606/rco.v2i2.347 05

Ozdil, E., \& Hoque, Z. (2017). Budgetary change at a university: A narrative inquiry. The British Accounting Review, 49(3), pp. 316-328. https://doi.org/10.1016/j.bar.2016.09.004

Paim, J. D. Q. (2017). Contribuiçôes das universidades comunitárias de Santa Catarina para o desenvolvimento regional na sociedade do conhecimento (Dissertação de mestrado). Universidade do Extremo Sul Catarinense, Criciúma, SC, Brasil. http://repositorio.unesc.net/handle/1/5473

Persson, E., \& Moretto, L. Neto (2020). Desenvolvimento Institucional em Organizações da Sociedade Civil: Gestão Social ou Gestão Estratégica do Social? Administração Pública E Gestão Social, 12(3). https://doi.org/10.2111 8/apgs.v12i3.5405

Raptopoulos, M. M. S. C., \& Silva, J. F. da. (2020). Avaliação Comparativa de Métodos de Mensuração e Avaliação de Desempenho para Organizações do Terceiro Setor. Administração Pública E Gestão Social, 12(4). https://d oi.org/10.21118/apgs.v12i4.6229

Reis, A. M. dos, \& Teixeira, A. J. C. (2013). Utilização de Artefatos de Contabilidade Gerencial nas Sociedades Cooperativas Agropecuárias de Minas Gerais e Sua Relação com Porte e Desempenho Financeiro. Revista De Educação E Pesquisa Em Contabilidade (REPeC), 7(4), pp. 355-371. https://doi.org/10.17524/repec.v7i4.997

Ribeiro, L., \& Timóteo, A. (2012). A Adoção dos Controles Internos em uma Organização do Terceiro Setor como Sustentabilidade Econômica: Um Estudo de Caso em uma Associação de Minas Gerais. Revista Contemporânea de Contabilidade, 9(17), pp. 61-82. https://doi.org/10.5007/2175-8069.2012v9n17p61

Russo, P. T., \& Guerreiro, R. (2017). Percepção sobre a sociomaterialidade das práticas de contabilidade gerencial. RAE-Revista de Administração de Empresas, 57(6), pp. 567-584. http://dx.doi.org/10.1590/S0034-75902017 0605

Russo, P. T., Parisi, C., \& Pereira, C. A. (2016). Evidências das forças causais críticas dos processos de institucionalização e desinstitucionalização em artefatos da contabilidade gerencial. Revista Contemporânea de Contabilidade, 13(30), pp. 3-33. http://dx.doi.org/10.5007/2175-8069.2016v13n30p3

Salamon, L. M., \& Anheier, H. K. (1997). Defining the nonprofit sector: A cross-national analysis. New York: Manchester University Press.

Saraiva, L. A. S., Duarte, A. C. O., de Magalhães, Y. T., \& Oliveira, D. A. (2011). Questões identitárias no terceiro setor: estudo de dois casos. Revista de Administração, Contabilidade e Economia da Fundace, 2(1). http://dx.d oi.org/10.13059/racef.v2i1.30

Silva, C. E. G. (2010). Gestão, legislação e fontes de recursos no terceiro setor brasileiro: uma perspectiva histórica. Revista de Administração Pública, 44(6), pp. 1301-1325. http://bibliotecadigital.fgv.br/ojs/index.php/rap/arti cle/view/6964

Silva, C. E. G., \& Aguiar, A. C. (2011). Avaliação de Atividades no terceiro setor de Belo Horizonte: da racionalidade subjacente às influências institucionais. Organizaçôes \& Sociedade, 18(56), pp. 35-56. http://www.redalyc.org/ articulo.oa?id $=400638314003$

Silveira, D., \& Borba, J. A. (2010). Evidenciação Contábil de Fundações Privadas de Educação e Pesquisa: Uma Análise da Conformidade das Demonstrações Contábeis de Entidades de Santa Catarina. Contabilidade Vista \& Revista, 21(1), 41-68. https://revistas.face.ufmg.br/index.php/contabilidadevistaerevista/article/view/815

Soares, S., Ramos, F., Casagrande, J., \& Nunes, N. (2019). Revisão integrativa da literatura brasileira sobre Contabilidade Financeira e Gerencial de organizações do Terceiro Setor. Revista Brasileira de Contabilidade, 239(1). pp. 68-89. 
Renícia Innocenti, et al. Práticas de Contabilidade Gerencial no Terceiro Setor: O Desafio da Gest...

Valadão, V. M., Malaquias, R. F., \& de Sousa, E. G. (2008). Controladoria como uma opção à sustentabilidade econômica nas organizaçóes de Terceiro Setor: o caso de uma associação. Revista Contemporânea de Contabilidade, 5(9), pp. 131-152. https://dialnet.unirioja.es/servlet/articulo?codigo=3166463

Voese, S. B., \& Reptczuk, R. M. (2011). Características e peculiaridades das entidades do terceiro setor. ConTexto, 11(19), pp. 31-42. https://www.seer.ufrgs.br/ConTexto/article/view/16314

Wanderley, C., \& Cullen, J. (2013). Management accounting change: A review. BASE-Revista de Administração e Contabilidade da Unisinos, 10(4), pp. 294-307. https://doi.org/10.4013/base.2013.104.01

Youssef, M. A. (2013). Management accounting change in an Egyptian organization: an institutional analysis. Journal of Accounting \& Organizational Change, 9(1), pp. 50-73. https://doi.org/10.1108/18325911311307203 